\title{
Physicochemical, structural characterization and pasting properties of pre-gelatinized Neorautanenia mitis starch
}

\author{
Olubunmi Olayemi ${ }^{1, A-F}$, Oladapo Adetunjii ${ }^{2, B-E}$, Christianah Isimi ${ }^{1, B, D-F}$ \\ ${ }^{1}$ Department of Pharmaceutical Technology and Raw Materials Development, National Institute for Pharmaceutical Research and Development, Abuja, Nigeria \\ ${ }^{2}$ Department of Pharmaceutics and Industrial Pharmacy, University of Ibadan, Nigeria \\ A - research concept and design; $\mathrm{B}$ - collection and/or assembly of data; $\mathrm{C}$ - data analysis and interpretation; \\ $D$ - writing the article; $E$ - critical revision of the article; $F$ - final approval of the article
}

Address for correspondence

Olubunmi Olayemi

E-mail: olubunmibiala@yahoo.co.uk

Funding sources

None declared

Conflict of interest

None declared

Received on April 23, 2021

Reviewed on May 7, 2021

Accepted on June 15, 2021

Published online on June 26, 2021

Cite as

Olayemi 0 , Adetunji 0 , Isimi C. Physicochemical, structural characterization and pasting properties of pre-gelatinized Neorautanenia mitis starch. Polim Med. 2021;51(1):7-16 doi:10.17219/pim/138964

DOI

10.17219/pim/138964

Copyright

C 2021 by Wroclaw Medical University

This is an article distributed under the terms of the

Creative Commons Attribution 3.0 Unported (CC BY 3.0)

(https://creativecommons.org/licenses/by/3.0/)

\begin{abstract}
Background. Pre-gelatinization is one of the most common physical methods of starch modification, which involves heating to bring about significant changes in the nature of starch, such as high swelling, loss of crystallinity, solubility in cold water, and improved pasting.
\end{abstract}

Objectives. To evaluate the structural and physicochemical properties of starch from Neorautanenia mitis tubers, and determine the effect of pre-gelatinization on the functional properties of this starch.

Materials and methods. Properties of the pre-gelatinized starch (NMPS), such as flow, swelling power, hydration capacity, pH, morphology, Fourier-infrared spectroscopy (FTIR), differential scanning calorimetry, and pasting characteristics, were compared with those of the native starch (NMNS).

Results. Pre-gelatinized starch had good flow with the angle of repose at $33.69^{\circ}$. Carr's index was $10.90 \%$ and $7.50 \%$, and the Hausner ratio was 1.12 and 1.05 for NMNS and NMPS, respectively. Both starches had neutral to near-neutral pH (7.00 and 6.04, respectively). The hydration capacity of NMPS (59.00\%) was about 2 times higher than that of NMNS (25.80\%), while the swelling power of NMPS between $40^{\circ} \mathrm{C}$ and $60^{\circ} \mathrm{C}$ was higher than that of NMNS, and maximum swelling for both starches was observed at $80^{\circ} \mathrm{C}$. Morphology showed that NMNS granules were discrete, smooth and spherical, while those of NMPS were aggregated, with rough surfaces. The FTIR spectra of both starches showed identical absorption peaks but the enthalpy of gelatinization differed for both starches. The pasting properties also varied significantly among the starch samples. Native starch had better peak viscosity, breakdown viscosity and pasting temperature, while NMPS presented better trough viscosity, final viscosity, setback viscosity, and pasting time.

Conclusions. The results showed that pre-gelatinized starch from N. mitis tubers possesses high swelling and hydration abilities and significant pasting properties, and may be used as a disintegrant in solid dosage formulations and in products requiring low viscosities and bond strength.

Key words: physicochemical properties, starch, structural, Neorautanenia mitis, pre-gelatinization 


\section{Background}

Starch is, after cellulose, the most abundant natural carbohydrate found in plants. It can be found in different plant parts, including the seeds, roots, stems, leaves, and fruits, as a ready source of energy. Being commonly found in plants, it is relatively abundant, cheap, safe, degradable, and easily modifiable. As such, starch is a material widely used in food, cosmetics and pharmaceutical industries. However, starch in its native form has limited application in industrial processes because of some of its undesirable inherent properties, such as poor processability, poor solubility in common organic solvents, retrogradation, low shear stress resistance, and susceptibility to thermal decomposition. ${ }^{1}$ Modification processes, such as enzymatic hydrolysis, chemical modifications and physical modifications, have been employed to develop new functional properties and to improve the inherent properties of starch. ${ }^{2}$

Physical methods of starch modification, like heat gelatinization, are commonly utilized because they do not require the use of chemicals and thus, are deemed safe for human consumption. ${ }^{3}$ Pre-gelatinization is one of the most popular physical methods of starch modification and it involves heating a starch suspension at a temperature below its gelatinization temperature. ${ }^{4}$ The process of pre-gelatinization causes an irreversible disruption of the starch granules by reorganizing the hydrogen bonding within them. This process is responsible for several changes in starch properties including high swelling, loss of crystallinity, solubility in cold water, and improved pasting and flow. ${ }^{5}$ These properties make pre-gelatinized starch suitable for many processes in the pharmaceutical and food industries. ${ }^{6}$

Starches from various plant sources have their own unique properties that are utilized to meet specific needs. Starch from Neorautanenia mitis is examined in this study. Neorautanenia mitis (A. Rich) Verdcourt of the Fabaceae family is a leguminous subshrubby plant with a tuberous rootstock. It is usually found growing in grasslands, bushy lands and open woodlands and rocky soils of the central, southern and western regions of Africa. ${ }^{7}$ Traditionally, this plant was used as a fish poison and an insecticide, and to treat skin infections, syphilis and psychiatric conditions. Experimental studies have also shown that it possesses acaricidal, antimicrobial and antinociceptive properties. ${ }^{8,9}$

Despite the therapeutic potentials of this plant, the starch that abounds in its tubers has not been documented to have nutritional value, nor has it been exploited for use as an excipient in the food, cosmetics or pharmaceutical industries. However, Olayemi et al. has examined the potential of starch from the tuberous roots of $N$. mitis to be used in tablet formulations. ${ }^{10}$

\section{Objectives}

In view of the fact that the traditional sources of starch are overexploited, tubers of $N$. mitis could be used as a new source of starch and starch derivatives. Therefore, the aim of this study is to prepare pre-gelatinized starch from tubers of $N$. mitis, and evaluate the structural, physicochemical and pasting properties of the modified starch, with a view to provide new starch sources with potential functional properties.

\section{Materials and methods}

The materials used included $N$. mitis tubers purchased from Suleja Community Market, Suleja, Nigeria. The $N$. mitis starch was prepared in the NIPRD Laboratory (Abuja, Nigeria). All other reagents used were of analytical grade.

\section{Extraction of starch}

Starch was extracted using a previously described method. ${ }^{10}$ Tubers of $N$. mitis were peeled, washed in water and diced. Then, they were soaked in a solution of sodium metabisulphite solution $(0.75 \% \mathrm{w} / \mathrm{v})$ for $2 \mathrm{~h}$ and ground using a blender. The blended mixture was sieved using a muslin cloth and the suspension was centrifuged at $1500 \mathrm{rpm}$ for $15 \mathrm{~min}$ in a centrifuge (Heraeus Sepatech Labofuge Ae, Münster, Germany). The supernatant was discarded and the sediment (starch) was air-dried at room temperature for $24 \mathrm{~h}$, and then pulverized in a mortar, packaged appropriately and stored in a desiccator.

\section{Pre-gelatinization of $N$. mitis native starch (NMNS)}

A previously described method for pre-gelatinization was adopted. ${ }^{11}$ A starch slurry (20\% w/v) was prepared in water and heated at $55^{\circ} \mathrm{C}$ in a water bath (Karl Kobb, Dreieich, Germany) with constant stirring for $15 \mathrm{~min}$. The resulting paste was dried in an oven (Biobase Biodustry Co. Ltd., Shandong, China) at $60^{\circ} \mathrm{C}$ for $48 \mathrm{~h}$ and sieved using a $250-\mu \mathrm{m}$ sieve mesh. The pre-gelatinized starch (NMPS) was stored in an airtight container and placed in a desiccator until further use.

\section{Evaluation of NMNS and NMPS}

\section{Morphology}

Starch samples (NMNS and NMPS) were mounted on metal stubs, coated with gold and analyzed using a scanning electron microscope (SEM; ASPEX 3020, PSEM 2; Field Electron and Ion, FEI Corp, Hilsboro, USA). Images of the starch surfaces were obtained at $\times 1000$ magnification at a current of $7 \mathrm{~mA}$ for $90 \mathrm{~s}$. 


\section{Fourier-transform infrared (FTIR) spectra studies}

The starches (NMNS and NMPS) were triturated with potassium bromide powder and were made into pellets $\left(1 \mathrm{ton} / \mathrm{cm}^{2}\right)$. Infrared (IR) spectra were obtained between scanning ranges of $4000 \mathrm{~cm}^{-1}$ and $400 \mathrm{~cm}^{-1}$ from a Magna-IR 560 spectrometer (Perkin Elmer, Waltham, USA).

\section{Gelatinization temperature}

The gelatinization temperature was determined using a differential scanning calorimeter (DSC; Model DSC 204 F1; Netzsch, Selb, Germany). Starch samples were placed in the aluminum pans of the equipment and scanned at between $60^{\circ} \mathrm{C}$ and $300^{\circ} \mathrm{C}$ at a heating rate of $10^{\circ} \mathrm{C} / \mathrm{min}$ under constant nitrogen flow.

\section{$\mathrm{pH}$ determination}

Slurries $(5 \% \mathrm{w} / \mathrm{v})$ of the starch samples were prepared in distilled water and the $\mathrm{pH}$ was measured at room temperature $\left(28^{\circ} \mathrm{C}\right)$ using a $\mathrm{pH}$ meter (Metler Toledo, Greifensee, Switzerland). Triplicate determinations were made and the average value was recorded.

\section{Swelling power}

Starch slurries $(1 \% \mathrm{w} / \mathrm{v})$ were prepared with distilled water and heated in a water bath at $40^{\circ} \mathrm{C}$ for $30 \mathrm{~min}$. The dispersions were centrifuged at $1500 \mathrm{rpm}$ for $30 \mathrm{~min}$, the supernatant was discarded, the weight of the starch paste was determined, and the swelling power (SP) was computed using the equation below:

$$
\text { SP }(\%)=\frac{\text { weight of starch paste }}{\text { initial weight of dry starch }} \times 100
$$

This procedure was repeated at $50^{\circ} \mathrm{C}, 60^{\circ} \mathrm{C}, 70^{\circ} \mathrm{C}, 80^{\circ} \mathrm{C}$, and $90^{\circ} \mathrm{C}$ for both starch samples.

\section{Hydration capacity}

The method of Kornblum and Stoopak ${ }^{12}$ was adopted to determine the starch hydration capacity (HC). Starch dispersions $(1 \% \mathrm{w} / \mathrm{v})$ were prepared with distilled water, poured into pre-weighed, stoppered centrifuge tubes and shaken intermittently for $10 \mathrm{~min}$. The tubes were allowed to stand for another $10 \mathrm{~min}$ at room temperature and then centrifuged at $1500 \mathrm{rpm}$ for $5 \mathrm{~min}$. The supernatant was discarded, and the weight of the sediment (hydrated starch) was determined and used to compute the $\mathrm{HC}$ as shown below:

$$
\mathrm{HC}=\frac{\text { initial weight of dry starch }}{\text { weight of hydrated starch }} \times 100
$$

\section{Flow properties}

\section{Angle of repose}

The angle of repose was determined using the funnel method. Twenty grams of starch sample were allowed to flow through the orifice of a funnel clamped at a fixed height from a flat surface. The height (h) and radius (r) of the heap formed were measured and used to compute the angle of repose (A) as shown below:

$$
\mathrm{A}=\tan ^{-1} \frac{\mathrm{h}}{\mathrm{r}}
$$

\section{Bulk and tapped densities}

The volume occupied by the starch samples (50 g) in a graduated measuring cylinder was noted as the bulk volume and used to compute the bulk density $[\mathrm{g} / \mathrm{mL}]$. In the same way, the volume occupied by the samples after tapping the measuring cylinder 100 times was noted and used to compute the tapped density $[\mathrm{g} / \mathrm{mL}]$. Triplicate determinations were made for each parameter and the average value was computed accordingly.

\section{Carr's compressibility index $(\mathrm{Cl})$ and Hausner ratio (HR)}

These were computed with data obtained from the bulk and tapped densities using the equations below:

$$
\begin{gathered}
C I=\frac{\text { tapped density }- \text { bulk density }}{\text { tapped density }} \times 100 \\
\mathrm{HR}=\frac{\text { tapped density }}{\text { bulk density }} \times 100
\end{gathered}
$$

\section{True density}

The liquid displacement method was adopted and liquid paraffin was used as the displacement fluid. Three determinations were made and the true density (Trd) was computed as shown below, where Wp is the weight of starch powder, $\mathrm{x}$ is the weight of the bottle and fluid, $y$ is the weight of the bottle, fluid and starch powder, and $\mathrm{SG}$ is the specific gravity of liquid paraffin $(0.865 \mathrm{~g} / \mathrm{mL})$.

$$
\operatorname{Trd}=\frac{\mathrm{Wp}}{[(\mathrm{x}+\mathrm{Wp})-\mathrm{y}] \times \mathrm{SG}} \times 100
$$

\section{Determination of pasting properties}

The pasting properties of the starches (NMNS and NMPS) were determined using a Rapid Visco-Analyzer 
(RVA; Perten Instruments, Macquarie Park, Australia). The method used previously by Shevkani et al. ${ }^{13}$ was adopted, but with slight modifications. Starch-water suspensions based on a dry starch basis of $25 \mathrm{~g}$ were used in monitoring the viscograms of the starches. The different batches of suspensions containing NMNS and NMPS were tested under similar temperature and time conditions.

\section{Results and Discussion}

The physicochemical properties of NMNS and NMPS are displayed in Table 1 . The angle of repose is a reflection of the flow ability of a material and values $<30^{\circ}$ indicate excellent flow, those between $31^{\circ}$ and $35^{\circ}$ show good flow, while values between $36^{\circ}$ and $40^{\circ}$ and $>40^{\circ}$ signify that the material exhibits fair and poor flow, respectively. ${ }^{14}$ This indirect measurement of the flow properties of the starches show that NMNS and NMPS had angles of repose of $38.60^{\circ}$ and $33.69^{\circ}$, respectively (Table 1), and indicate that pre-gelatinization improved flow of the starch powder.

The ability of both starches to deform under pressure was computed using CI. Materials with a $\mathrm{CI} \leq 10 \%$ are considered to have excellent flow, those between $11 \%$ and $15 \%$ - good flow, between $16 \%$ and $20 \%$ - fair, and those $>25 \%$ - poor flow. On the other hand, the measure of material cohesiveness, which depicts the degree of densification, was determined with the HR. Values $\leq 1.11$ show that the material is cohesive, and it is less cohesive when HR values are between 1.12 and $1.20 .^{15}$ The CI of NMNS was found to be $10.97 \%$ and that of NMPS was $7.50 \%$, while the HR was 1.12 and 1.05 , respectively. These results indicate that both starches exhibit good flow. However, the process of pre-gelatinization improved the flow characteristics of NMPS appreciably. The Trd of NMPS (1.39) was higher than that of NMNS (0.89), suggesting an increased ability of NMNS to promote even packing when confined into processing spaces such as compaction or tableting dies. ${ }^{16}$ The ability of materials to flow

Table 1. Physicochemical properties of NMNS and NMPS $(n=3$, mean \pm SD)

\begin{tabular}{|lcc|}
\multicolumn{1}{|c|}{ Parameter } & NMNS & NMPS \\
\hline Angle of repose $\left[{ }^{\circ}\right]$ & 38.60 & 33.69 \\
Bulk density $[\mathrm{g} / \mathrm{mL}]$ & $0.61 \pm 0.02$ & $0.63 \pm 0.02$ \\
Tapped density $[\mathrm{g} / \mathrm{mL}]$ & $0.69 \pm 0.01$ & $0.66 \pm 0.01$ \\
Hausner ratio & $1.12 \pm 0.04$ & $1.05 \pm 0.04$ \\
Carr's index $[\%]$ & $10.97 \pm 2.91$ & $7.50 \pm 0.00$ \\
True density $[\mathrm{g} / \mathrm{mL}]$ & $0.89 \pm 0.07$ & $1.39 \pm 0.03$ \\
Hydration capacity $[\%]$ & $25.80 \pm 0.04$ & $59.00 \pm 0.23$ \\
pH & $7.00 \pm 0.11$ & $6.04 \pm 0.50$ \\
\hline
\end{tabular}

SD - standard deviation; NMNS - native starch; NMPS - pre-gelatinized starch. is dependent on the particle size, shape and distribution of the particles in the material. Disruption of the starch granules and consequent agglomeration due to gelatinization (Fig. 1) produces voids within and between the particles. This reduces the friction between particles and allows for better flow, which invariably influences the packing behavior of the starches. Adequate/good flow is highly recommended in high-speed tableting/capsule filling machines as this ensures that the die cavities are uniformly filled, giving rise to tablets/capsules of uniform weight and uniform content.

The $\mathrm{pH}$ of the starches was 7.00 and 6.04 for NMNS and NMPS, respectively (Table 1), and falls with the specification of between 4.5 and 7.0 for starch solutions. ${ }^{17}$ The near-neutral $\mathrm{pH}$ of both starches implies that problems with irritability in the gastrointestinal tract might not arise from the use of these starches, and therefore, they would be desirable for use in oral formulations. ${ }^{18}$ The lower $\mathrm{pH}$ of NMPS observed in this study, which may be attributed to the modification process, is in agreement with a previous report by Azubuike et al. ${ }^{11}$ that examined pre-gelatinized Borassus aethipom starch.

The HC signifies the total amount of water that is retained by starch gel under defined conditions like pressure or heat. ${ }^{19}$ Pre-gelatinized starch was observed to have the ability to retain twice the weight of water retained by NMNS (Table 1), and the HC of NMNS was $25.80 \%$ while that of NMPS was $59.00 \%$. The increase observed in NMPS can be attributed to the loss of crystalline association in the granules, leading to more available binding sites for water. ${ }^{20}$ The process of pre-gelatinization reduces the molecular weight of starch granules resulting in the ability to attract more water molecules and swell as compared to un-gelatinized starches. ${ }^{21}$ Materials with high HCs such as NMPS have been documented to be useful as disintegrants because of their increased ability to absorb water and swell, which is part of the mechanism of action of starch as a disintegrant. ${ }^{22}$

Swelling is an important characteristic that reveals the ability of starch granules to absorb water. Investigating the swelling behavior of starch within different temperature ranges is important as it evaluates the performance of a starch under industrial conditions. Table 2 shows that swelling power of both starches increased with an in-

Table 2. Swelling power [\%] of starches at different temperatures

\begin{tabular}{|c|c|c|} 
Temperature $\left[{ }^{\circ} \mathrm{C}\right]$ & NMNS & NMPS \\
\hline 40 & 27.10 & 55.20 \\
50 & 27.90 & 62.10 \\
60 & 56.00 & 70.70 \\
70 & 144.80 & 112.20 \\
80 & 148.20 & 112.50 \\
90 & 75.50 & 87.10 \\
\hline
\end{tabular}

NMNS - native starch; NMPS - pre-gelatinized starch. 

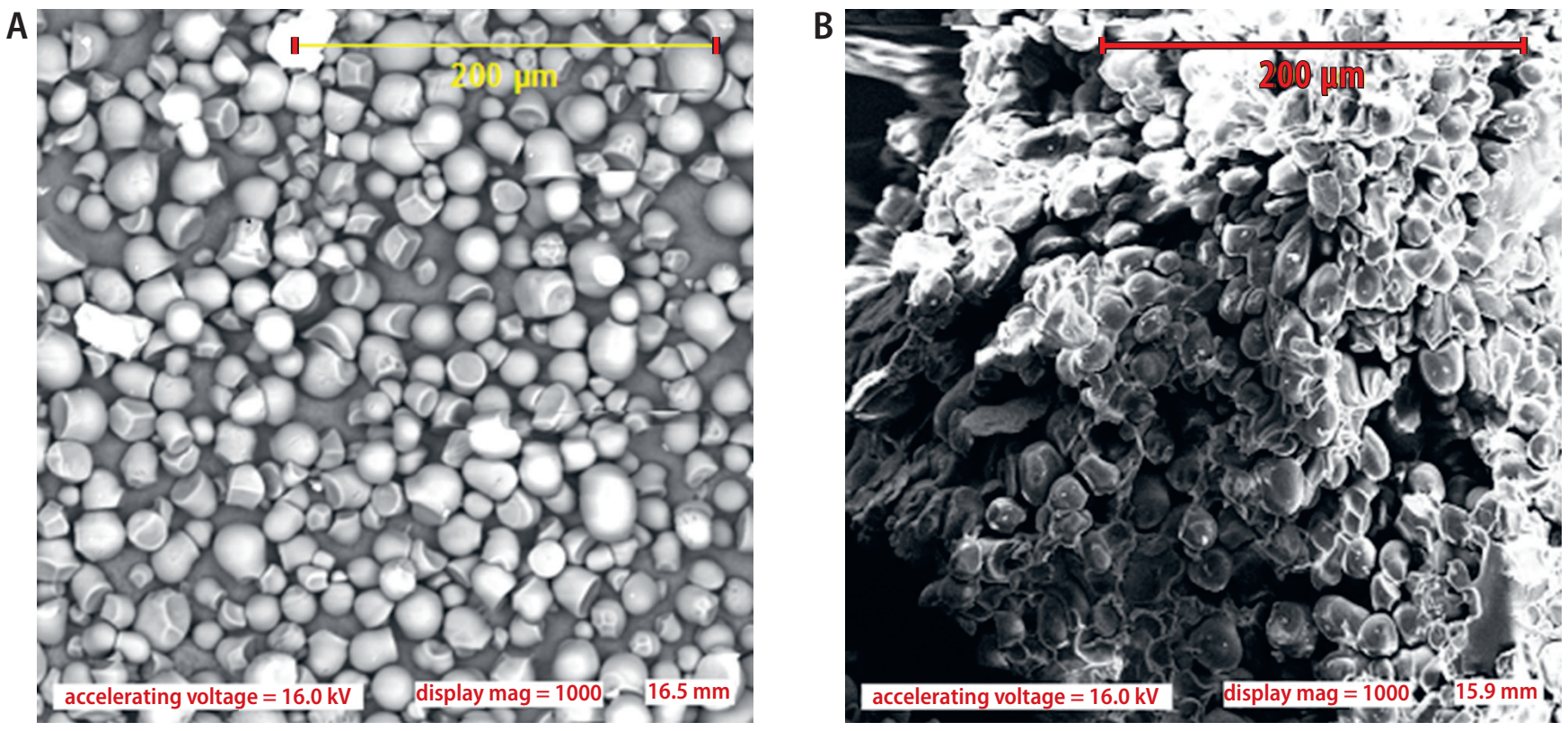

Fig. 1. SEM images of native N. mitis starch (NMNS) (A) and pre-gelatinized N.mitis starch (NMPS) (B)

crease in temperature up to $80^{\circ} \mathrm{C}$, with more pronounced swelling occurring at higher temperatures $\left(70^{\circ} \mathrm{C}\right.$ and $\left.80^{\circ} \mathrm{C}\right)$ than within lower temperature ranges (between $40^{\circ} \mathrm{C}$ and $60^{\circ} \mathrm{C}$ ). Increased swelling at higher temperatures has been ascribed to a weakening of the intrinsic binding forces in the amorphous regions of the starch granules at varying temperatures. ${ }^{23}$ Swelling was also found to be higher between $40^{\circ} \mathrm{C}$ and $60^{\circ} \mathrm{C}$ in NMPS than in NMNS. This effect can be ascribed to the destruction of the regular structure of the NMPS during pre-gelatinization, which conferred on it the ability to imbibe water increased over the temperatures. Swelling was observed to decrease considerably at $90^{\circ} \mathrm{C}$ to $75.50 \%$ and $87.10 \%$ for NMPS and NMNS, respectively, and can be attributed to total loss of granule structure and rupture of the granules. ${ }^{24}$ This suggests that the maximum swelling temperature for both starches is $80^{\circ} \mathrm{C}$, and can serve as a guide in determining where and how these starches (NMNS and NMPS) can be used.

Microscopic observation of the starches using SEM revealed that NMNS is discrete, smooth, non-porous, and almost spherical in shape (Fig. 1A), while the shape of NMPS is non-discrete, gel-like, rough, and irregular (Fig. 1B). Granules of pre-gelatinized starch (Fig. 1B) were also observed to be aggregated, which is due to granular disintegration and the subsequent release of soluble components during the thermal process of gelatinization. The particle sizes measured with SEM were $16.5 \mathrm{~mm}$ and $5.9 \mathrm{~mm}$ for NMNS and NMPS, respectively. Heating starch has been postulated to affect swelling and rupture of starch granules, which invariably affects the size of the resulting starch product. ${ }^{25}$ Furthermore, the heating process may have caused the loss of the amylopectin crystalline region, with the consequent rearrangement of bonds within the granules leading to breakdown, distortion and loss of granule integrity. These observations are in line with similar studies showing the effects of pregelatinization on starch morphology. ${ }^{26,27}$

The FTIR spectra of NMNS and NMPS scanned in the 4000-400 $\mathrm{cm}^{-1}$ range are displayed in Fig. 2 and 3 , while the absorption peaks and corresponding peak heights for NMNS and NMPS are presented in Tables 3 and 4 , respectively.

Broad bands observed in both spectra at about $3800 \mathrm{~cm}^{-1}$ and $3000 \mathrm{~cm}^{-1}$ correspond to $\mathrm{O}-\mathrm{H}$ stretching of hydrogen bonded hydroxyl groups, which may be ascribed to the presence of intra- and intermolecular hydrogen bonds in the starch granules. ${ }^{28}$ The spectra of NMPS (Fig. 3) shows a stronger, broader O-H stretch at about $3800 \mathrm{~cm}^{-1}$ with a peak height of 17.29 (Table 4) that is about 3 times higher than that of NMNS (6.88;

Table 3. Absorption peaks and corresponding heights of native starch

\begin{tabular}{|c|c|}
\hline Peak at $\left[\mathrm{cm}^{-1}\right]$ & Peak height \\
\hline 938.40 & 25.14 \\
1460.80 & 18.75 \\
1938.40 & 17.44 \\
2361.60 & 8.74 \\
3803.20 & 6.88 \\
\hline
\end{tabular}

Table 4. Absorption peaks and corresponding heights of pre-gelatinized starch

\begin{tabular}{|c|c|}
\hline Peak at $\left[\mathrm{cm}^{-1}\right]$ & Peak height \\
\hline 938.40 & 32.23 \\
1460.00 & 26.83 \\
1930.40 & 25.34 \\
2362.40 & 8.45 \\
3802.40 & 17.29 \\
\hline
\end{tabular}




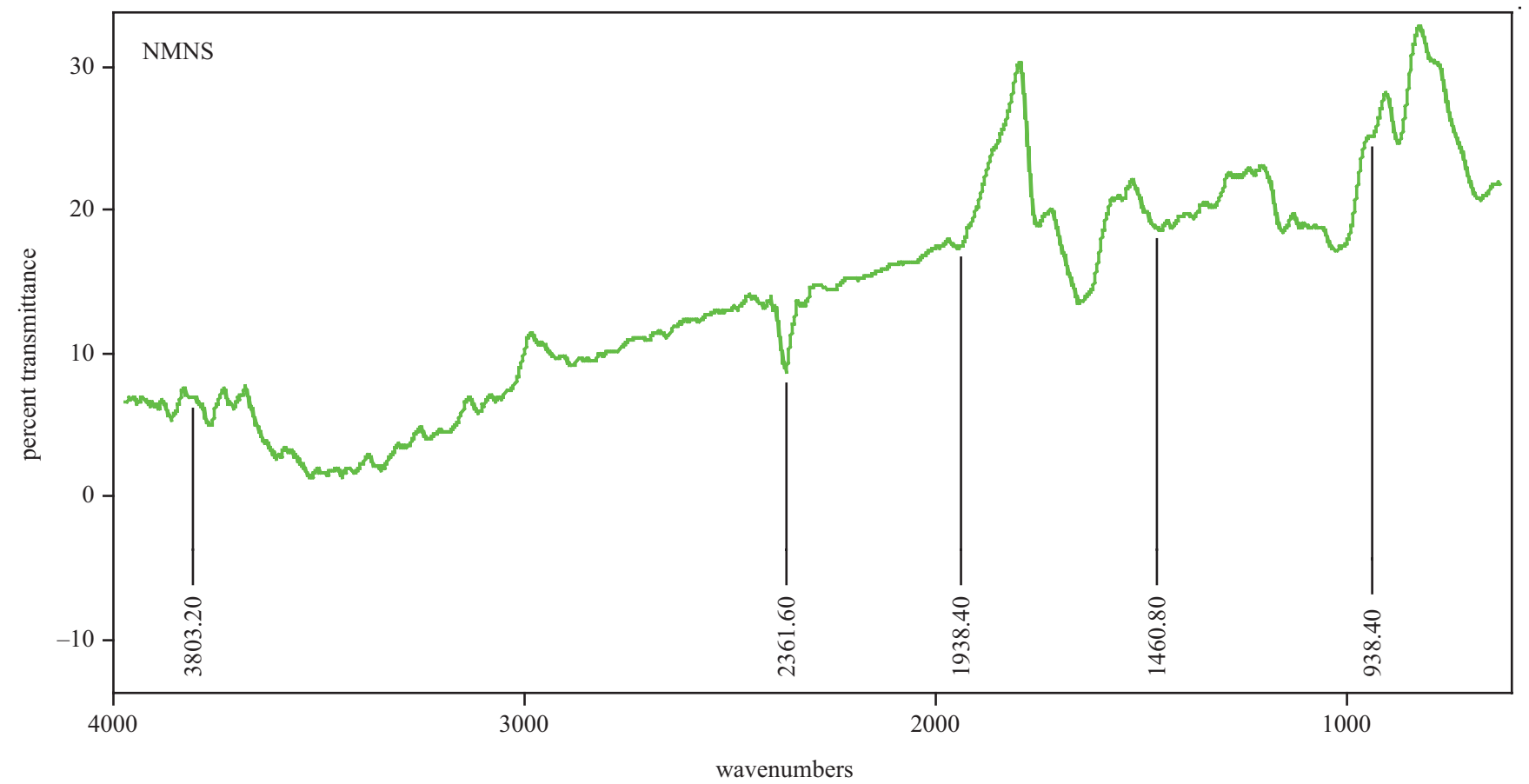

Fig. 2. FTIR spectra of native N. mitis starch (NMNS)

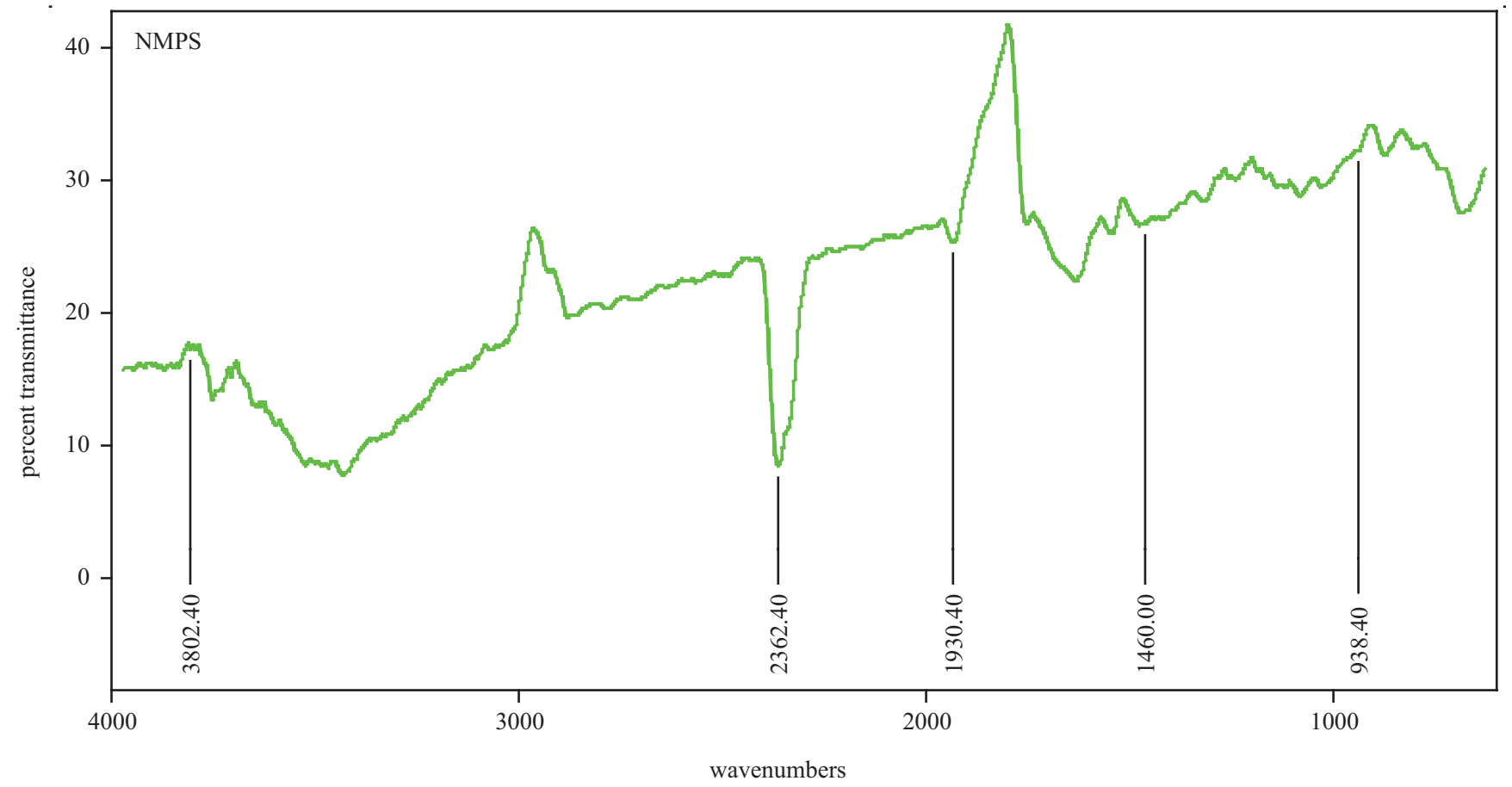

Fig. 3. FTIR spectra of pre-gelatinized N. mitis starch (NMPS)

Table 3). This can be attributed to the higher swelling capacity observed for NMPS. Vibrations at $3000 \mathrm{~cm}^{-1}$ and $2800 \mathrm{~cm}^{-1}$ are characteristic of $\mathrm{C}-\mathrm{H}$ stretches associated with ring hydrogen atoms, and this vibration was observed to be intense in the spectra of NMPS. Previous studies have shown that such changes in modified starches are attributed to changes in the ratio of amylose to amylopectin, with a consequent influence on the physicochemical properties of the starch. ${ }^{29}$
Vibrations at about $2300 \mathrm{~cm}^{-1}$, which represent $\mathrm{C}-\mathrm{H}$ stretch for the alkane group of compounds, were found to be similar for both starches (Tables 3,4). Absorption peaks at about $1930 \mathrm{~cm}^{-1}$ (Fig. 2,3) correspond to scissors vibrations of $\mathrm{O}-\mathrm{H}$ bonds as a result of water of hydration in the starches. However, vibrations in NMPS were observed to be stronger as evidenced by a sharper peak. Vibrations at about $1460 \mathrm{~cm}^{-1}$ are related to $\mathrm{C}-\mathrm{H}$ bending and both peaks were observed to be more intense 


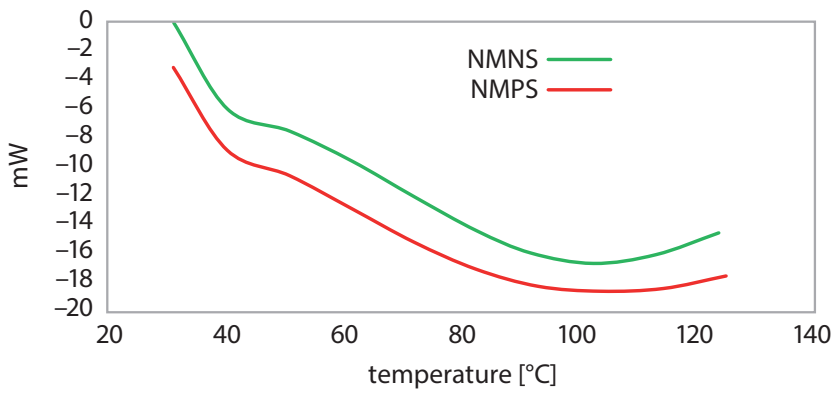

Fig. 4. Differential scanning calorimeter (DSC) thermogram of native N. mitis starch (NMNS) and pre-gelatinized N. mitis starch (NMPS)

in NMPS than NMNS. Vibrations at about $930 \mathrm{~cm}^{-1}$ are the skeletal absorptions of $\alpha-1,4$ glycosidic linkage characteristic of all polysaccharides, consisting of $\mathrm{COH}$ and $\mathrm{C}-\mathrm{O}-\mathrm{C}$ glycosidic stretching and bending. ${ }^{30}$ These vibrations were observed at the same absorption wave number for both starches and depict similarity in the basic fingerprint of both starches. The last region has been defined as the characteristic fingerprint of materials like starches. ${ }^{31}$

The results from FTIR spectroscopy show that pregelatinization did not introduce any new functional groups. However, this process affected the arrangement of the molecules in the starch particles as evidenced by the shifting of some of the bands.

The behavior of NMNS and NMPS when subjected to heat was determined with DSC and the thermograms are displayed in Fig. 4. The thermal properties of the starches such as onset temperature, peak temperature, conclusion temperature, and gelatinization enthalpy, among others, are presented in Table 5.

Although starch granules are insoluble in cold water, heat treatment in the presence of water causes gelatinization, which involves swelling of the granules, melting of the crystallite double helices, leaching of amylose, and consequent disintegration of the granules. ${ }^{32}$ This transitional phase of starch granules is a distinguishing property of individual starches that allows for their application in industrial processes.

Enthalpy of gelatinization $(\Delta \mathrm{H})$ gives an inclusive measure of the quantity and quality of crystallinity in starch granules, and is an indicator of the loss of molecular order within the granule that occurs with gelatinization. ${ }^{33}$
In other words, $\Delta \mathrm{H}$ is related to the energy required to disrupt starch granules and is a reflection of the heat involved in breaking the bonds between starch granules. The outcome of gelatinization is influenced by shape, amylopectin chain length and crystalline portions of the starch. ${ }^{34}$

Table 5 shows that NMPS has a lower $\Delta \mathrm{H}(5.27) \mathrm{com}-$ pared to NMNS (6.38). This could be attributed to the fact that some double helices in NMPS may have been disrupted during the process of pre-gelatinization. Therefore, lower energy was required to initiate the gelatinization process of the starch granule. Furthermore, weakening of the starch granules during pre-gelatinization could have resulted in early rupture of the amylopectin helices, leading to the observed lower values for onset temperature (To), conclusion temperature (Tc) and peak temperature (Tp). Similar results have also been reported regarding some other modified starches. ${ }^{35,36}$

In addition, since $\Delta \mathrm{H}$ reflects melting of the crystalline region of the starch granules, the low values observed for NMPS may also be connected with low crystalline association within starch granules, indicating that less crystalline portions are present. ${ }^{37,38}$ The degree of crystallinity of starch is known to be directly related to its granule strength, and demonstrates the extent to which the bond order within the starch molecule is broken and melted during the heating process. ${ }^{39}$ High $\Delta \mathrm{H}$ shows that higher energy is required to disrupt the bond order because of the presence of strong bonds between the granules. However, a low $\Delta \mathrm{H}$, as observed for NMPS, shows that lower energy was required to break the bonds due to the rupture of the starch granules during the process of gelatinization.

The application of heat in an ordered manner and the analysis of the obtained viscograms are the measures that enable determining the pasting properties. When heat is applied to starch, there is a transformation of the granules from an initial ordered state to a randomized, but disordered state, which is a result of the swelling of the granules. ${ }^{40}$ Starch granules are usually saturated with water, but as heat is applied, the granules begin to swell and the water that has been imbibed in the granule aids melting of the crystal lattice of the starch, thus creating room for rapid movement of water between the granules and within the granules. Subsequently, more water molecules bind to the starch granules, while the swelling reduces

Table 5. Thermal properties of NMNS and NMPS

\begin{tabular}{|l|c|c|}
\multicolumn{1}{c|}{ Parameter } & Peak height for NMNS & Peak height for NMPS \\
\hline Onset temperature $\left[{ }^{\circ} \mathrm{C}\right]$ & 31.19 & 30.58 \\
Peak temperature $\left[{ }^{\circ} \mathrm{C}\right]$ & 92.40 & 89.86 \\
Conclusion temperature $\left[{ }^{\circ} \mathrm{C}\right]$ & 156.89 & 159.06 \\
Enthalpy of gelatinization $\left[\mathrm{J} /\left(\mathrm{g}^{*} \mathrm{~K}\right)\right]$ & 6.38 & 5.27 \\
$\Delta \mathrm{T}$ (gelatinization temperature range) $\left[{ }^{\circ} \mathrm{C}\right]$ & 125.70 & 128.48 \\
\hline
\end{tabular}

NMNS - native starch; NMPS - pre-gelatinized starch. 
Table 6. Pasting properties of NMNS and NMPS $(n=3$, mean \pm SD)

\begin{tabular}{|c|c|c|c|c|c|c|c|}
\hline $\begin{array}{l}\text { Starch } \\
\text { sample }\end{array}$ & $\begin{array}{l}\text { Peak viscosity } \\
{[\mathrm{cP}]}\end{array}$ & $\begin{array}{c}\text { Trough viscosity } \\
{[\mathrm{CP}]}\end{array}$ & $\begin{array}{c}\text { Breakdown } \\
\text { viscosity } \\
{[\mathrm{CP}]}\end{array}$ & $\begin{array}{c}\text { Final viscosity } \\
{[\mathrm{CP}]}\end{array}$ & $\begin{array}{c}\text { Setback } \\
\text { viscosity } \\
{[c P]}\end{array}$ & $\begin{array}{l}\text { Peak } \\
\text { time } \\
\text { [min] }\end{array}$ & $\begin{array}{c}\text { Pasting } \\
\text { temperature } \\
{\left[{ }^{\circ} \mathrm{C}\right]}\end{array}$ \\
\hline NMNS & $745.33 \pm 0.20$ & $250.08 \pm 0.02$ & $495.25 \pm 0.13$ & $360.75 \pm 0.16$ & $110.67 \pm 0.05$ & $3.80 \pm 0.13$ & $76.8 \pm 0.06$ \\
\hline NMPS & $585.17 \pm 0.11$ & $407.83 \pm 0.12$ & $177.33 \pm 0.02$ & $689.75 \pm 0.12$ & $281.92 \pm 0.02$ & $4.67 \pm 1.02$ & $75.9 \pm 0.01$ \\
\hline
\end{tabular}

SD - standard deviation; NMNS - native starch; NMPS - pre-gelatinized starch.

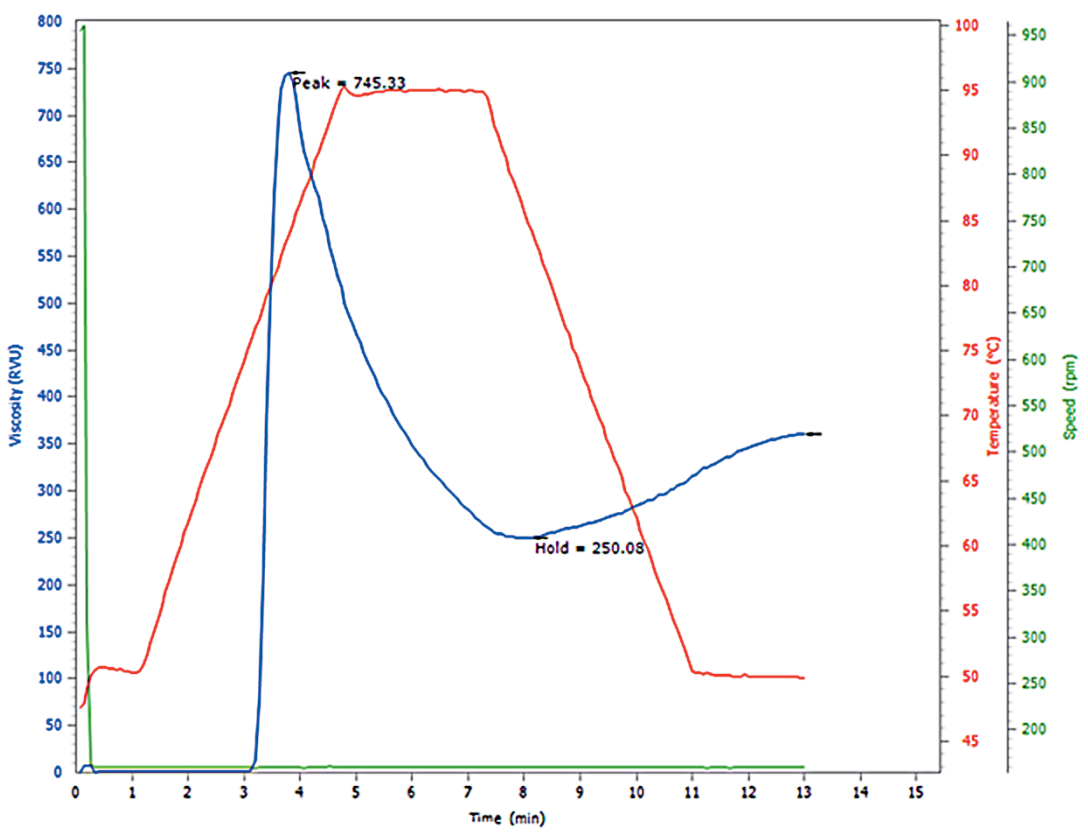

Fig. 5. Pasting profiles of native N. mitis starch (NMNS) and pre-gelatinized N. mitis starch (NMPS)

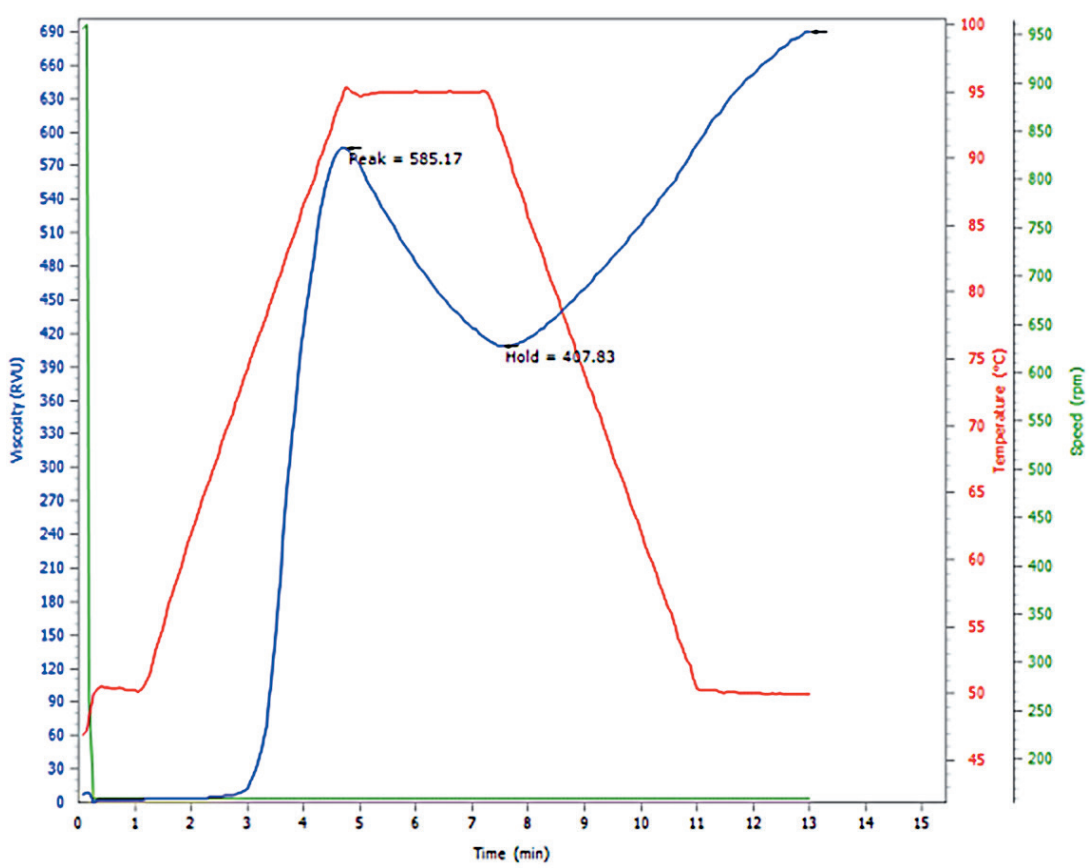

the available water, resulting in physical interactions between the granules. These interactions lead to changes in the viscosity of the starch.

The pasting profiles and properties (derived from the viscograms) of NMNS and NMPS are shown in Fig. 5 and Table 6, respectively. The pasting properties varied significantly among the starch samples. Native starch had better peak viscosity, breakdown viscosity and pasting temperature, while NMPS presented better trough viscosity, final viscosity, setback viscosity, and pasting time.

The high peak viscosity observed for NMNS (745.33 cP) may be due to the nonporous nature of the NMNS gran- 
ules, leading to a greater volume of water within the crystal lattice and, consequently, a higher viscosity compared to the NMPS granules. Degradation of starch granules as a result of pre-gelatinization is responsible for reduced viscosity against shear stress, ${ }^{41}$ as observed in NMPS. The measure of peak viscosity, which is associated with the rate at which granule swelling equals granule breakdown, is slower for NMNS than for NMPS based on the aggregation of granules, as observed from the morphology using SEM. Granules of NMPS were more compact than those of NMNS and could account for the higher trough viscosity observed for NMPS. Trough viscosity reflects paste viscosity due to the disruption of starch granules upon heating and was observed to be higher in NMPS than NMNS as a result of the compactness of the granules.

Breakdown viscosity is a measure of the degree of disintegration of gelatinized starch granules during heating. ${ }^{42}$ The already gelatinized NMPS is thus expected to have a lower breakdown viscosity than NMNS due to the reduction in starch granules available for further disintegration to take place. The final viscosity indicates the stability of starch pastes to heat. ${ }^{43}$ The results show that NMPS exhibited a higher final viscosity $(689.75 \mathrm{cP})$ than NMNS $(360.75 \mathrm{cP})$, indicating that pastes from NMPS are more stable to heat than those from NMNS. In addition, final viscosity reflects the resistance of the starch paste to flow. The lower value observed for NMNS suggests its flow ease, which could be a result of more water molecules available within the crystal lattice of NMNS than in NMPS, while NMPS exhibited a higher resistance to shear and flow. Such high final viscosity and low breakdown viscosity properties have been described as desirable for many food and industrial processes. ${ }^{44}$

The setback viscosity is exhibited due to recrystallization of the amylose molecules in the ge ${ }^{45}$ and shows the tendency for retrogradation to occur. Although NMPS, which has a higher resistance to flow, would be expected to exhibit low setback viscosity because of the disruption of amylose molecules that took place during the pre-gelatinization process, the setback viscosity of NMPS $(281.92 \mathrm{cP})$ was higher than that of NMNS $(110.67 \mathrm{cP})$. This could suggest the tendency of NMPS to undergo some form of gelling upon cooling, a phenomenon that has also been demonstrated when pregelatinized cassava and rice starch were blended together. ${ }^{46}$ The temperature at which the viscosity of the starch material begins to increase during the heating process is known as the pasting temperature. According to Salman et al., ${ }^{47}$ high pasting temperature is an indication of a high degree of crystallinity of starch molecules. The crystal lattice in the NMNS was more ordered than in the NMPS, which was disoriented due to pre-gelatinization, thus accounting for NMNS having a slightly higher pasting temperatures. However, the pasting temperatures of NMNS and NMPS were not significantly different. Visco-analysis shows that pre-gelatinization changed the pasting properties of native starch extracted from the tubers of $N$. mitis.

\section{Conclusions}

In this study, we have been able to modify starch from an underutilized crop, $N$. mitis tubers, by pre-gelatinization. Pre-gelatinization improved the flow properties, and increased the absorption capacity and SP, as observed with other pre-gelatinized starches. However, the granule strength was found to decrease. The pre-gelatinized $N$. mitis starch also exhibited peculiar pasting behavior with low viscosities but good thermal stability, as has been reported for other pre-gelatinized starches. The findings of the present study show that pre-gelatinized $N$. mitis starch may be applicable for food, cosmetics and pharmaceutical products where high swelling/hydration, low viscosity and low bond strength are required. However, further research to determine crystallinity and the molecular weight of the native and pre-gelatinized starches may be conducted.

\section{ORCID iDs}

Olubunmi Olayemi (D) https://orcid.org/0000-0001-5759-7176 Oladapo Adetunji (i) https://orcid.org/0000-0002-3474-0029 Christianah Isimi (D) https://orcid.org/0000-0002-9066-9984

\section{References}

1. Siregar C, Saleh W. Pharmaceutical Tablet Dosage Technology. Basics of Practical. Jakarta, Indonesia: Medical Book Publishers EGC; 2010.

2. Chen $\mathrm{Q}, \mathrm{Yu} \mathrm{H}$, Wang $\mathrm{L}$, et al. Recent progress in chemical modification of starch and its applications. RSC Adv. 2015;5(83):67459-67474. doi:10.1039/C5RA10849G

3. Kaur B, Ariffin F, Bhat R, Karim AA. Progress in starch modification in the last decade. Food Hydrocoll. 2012;26(2):398-404. doi:10.1016/j. foodhyd.2011.02.016

4. Rowe RC, Paul JS, Sian CO. Handbook of Pharmaceutical Excipient. $5^{\text {th }}$ ed. London, UK: The Pharmaceutical Press and Pharmaceutical Pharmacist Association; 2006.

5. Anastasiades A, Thanou S, Loulis D, Stapatoris A, Karapantsios TD. Rheological and physical characterization of pregelatinized maize starches. J Food Eng. 2002;52:57-66. doi:10.1016/S0260-8774(01)00086-3

6. Pramulani ML, Ari W, Hani A. The effect of pregelatinized taro starch (Colocasia esculenta (I.) schott) temperature as filler on thiamine hydrochloride tablet. Open Access Macedonian J Med Sci. 2019;7(22): 3827-3832. doi:10.3889/oamjms.2019.513

7. Burkill HM. The Useful Plants of West Tropical Africa. Vol. 3 (J-L). Kew, UK: Royal Botanic Garden; 1995:1400-1410.

8. Vongtau HO, Abbah J, Mosugu O, et al. Antinociceptive profile of the methanolic extract of Neorautanenia mitis root in rats and mice. J Ethnopharmacol. 2004;92:317-324. doi:10.1016/j.jep.2004.03.014

9. Lasisi AA, Adesomoju A. Neoraudiol: A new isoflavonoid and other antimicrobial constituents from the tuberous root of Neorautanenia mitis (A. Rich) verdcourt. J Saudi Chem Soc. 2015;19:404-409. doi:10. 1016/j.jscs.2012.04.011

10. Olayemi OJ, Ekunboyejo A, Bamiro OA, Kunle OO. Evaluation of disintegrant properties of Neorautanenia mitis starch. J Phytomed Ther. 2016;15(2):53-64.

11. Azubuike $\mathrm{CP}$, Ubani-Ukoma U, Madu SJ, Yomi-Faseun O, Yusuf S. Characterization and application of Borassus aethiopum (Arecaceae) shoot pre-gelatinized starch as binding agent in paracetamol tablets. J Rep Pharm Sci. 2019;8:172-180. doi:10.4103/jrptps.JRPTPS_29_18

12. Kornblum SS, Stoopak SB. A new tablet disintegrating agent: Crosslinked polyvinylpyrrolidone. J Pharm Sci. 1973;62(1):43-49. doi:10. 1002/jps.2600620107

13. Shevkani K, Singh N, Bajaj R, Kaur A. Wheat starch production, structure, functionality and applications: A review. Int J Food Sci Technol. 2017;52(1):38-58. doi:10.1111/ijfs.13266 
14. Mohammadi MS, Harnby N. Bulk density modelling as a means of typifying the microstructure and flow characteristics of cohesive powders. Powder Technol. 1997;92(1):1-8. doi:10.1016/S0032-5910(96)03254-8

15. Lefnaoui S, Moulai-Mostefa N. Synthesis and evaluation of the structural and physicochemical properties of carboxymethyl pre-gelatinized starch as a pharmaceutical excipient. Saudi Pharm J. 2015; 23(6):698-711. doi:10.1016/j.jsps.2015.01.021

16. Eraga SO, Ndukwe JO, Iwuagwu MA. An investigation of the direct compression properties of pre-gelatinized African bitter yam and cassava starches in acetylsalicylic acid tablet formulations. J App Sci Environ Manag. 2017;21(5):855-862. doi:10.4314/jasem.v21i5.10

17. British Pharmacopoeia Commission. British Pharmacopoeia. London, UK: TSO Publishers; 2017.

18. Hassan LG, Muhammad AB, Aliyu RU, et al. Extraction and characterization of starches from four varieties of Mangifera indica seeds. IOSR J AppI Chem. 2013;3(6):16-23. doi:10.9790/5736-0361623

19. Lawal OS. Composition, physico-chemical properties and retrogradation, characteristics of native, oxidized, acetylated and acid thinned new cocoyam (Xanthosoma sagittifolium) starch. Food Chem. 2004; 87(2):205-218. doi:10.1016/j.foodchem.2003.11.013

20. Manmeet-Kaur DPS, Oberoi DS, Sogi BSG. Physicochemical, morphological and pasting properties of acid treated starches from different botanical sources. J Food Sci Technol. 2010;48(4):460-465. doi:10.1007/s13197-010-0126-x

21. Adeyanju O, Olademehin OP, Hussaini Y, Nwanta UC, Adejoh Al, Plavec J. Synthesis and characterization of carboxymethyl Plectranthus esculentus starch: A potential disintegrant. J Pharm Appl Chem. 2016;2(3):189-195. doi:10.18576/jpac/020309

22. Adedokun MO, Itiola OA. Disintegrant activities of natural and pregelatinized trifoliate yams, rice and corn starches in paracetamol tablets. J App/ Pharm Sci. 2011;1(10):200-206. http://japsonline.com/ admin/php/uploads/328_pdf

23. Pérez $S$, Bertoft $E$. The molecular structures of starch components and their contribution to the architecture of starch granules: A comprehensive review. Starch/Stärke, 2010;62:389-420. doi:10.1002/star. 201000013

24. Sunarti TC, Richana N, Purwoko FK, Budiyanto A. The Characterization of Physicochemical Properties of Flour and Starch of National Varieties Corn and Filing of the Enzyme and Acid. The Research Report. Bogor, Indonesia: Bogor Agricultural Institute; 2007.

25. Ambigaipalan P, Hoover R, Donner E, et al. Structure of faba bean, black bean and pinto bean starches at different levels of granule organization and their physicochemical properties. Food Res Int. 2011;44(9):2962-2974. doi:10.1016/j.foodres.2011.07.006

26. Wijanarka A, Sudargo T, Harmayani E, Marsono Y. Effect of pre-gelatinization on physicochemical and functional properties of gayam (Inocarfus fagifer Forst.) flour. Am J Food Technol. 2017;12:178-185. doi:10.3923/ajft.2017.178.185

27. Adewumi FD, Lajide L, Adetuyi AO, Ayodele O. Synthesis and characterization of native and pre-gelatinized cassava starches. Am J Innov Res App/ Sci. 2019;9(4):418-424.

28. Ferreira-Villadiegoa J, García-Echeverria J, Vidala MV, et al. Chemical modification and characterization of starch derived from plantain (Musa paradisiaca) peel waste, as a source of biodegradable material. Chem Eng Trans. 2018;65:763-768. doi:10.3303/CET1865128

29. Olayemi B, Isimi C, Ekere K, Ajeh IJ, Okoh JE, Emeje MO. Green preparation of citric acid crosslinked starch for improvement of physicochemical properties of Cyperus starch. Turkish J Pharm Sci. 2021; 18(1):34-43. doi:10.4274/tjps.galenos.2019.65624

30. Oniszczuk T, Combrzyński M, Matwijczuk A, et al. Physical assessment, spectroscopic and chemometric analysis of starch-based foils with selected functional additives. PLoS One. 2019;14(2):e0212070. doi:10.1371/journal.pone.0212070
31. Ohwoavworhua FO, Osinowo A. Preformulation studies and compaction properties of a new starch-based pharmaceutical aid. Res J Pharm Biol Chem Sci. 2010;1:255-270.

32. Šárka E, Dvořáček V. New processing and applications of waxy starch (a review). J Food Eng. 2017;206:77-87. doi:10.1016/j.jfoodeng. 2017.03.006

33. Cooke D, Gidley MJ. Loss of crystalline and molecular order during starch gelatinization: Origin of the enthalpic transition. Carbohydr Res. 1992;227:103-112. doi:10.1016/0008-6215(92)85063-6

34. Singh N, Kaur L. Morphological, thermal, rheological and retrogradation properties of starch fractions varying in granule size. J Sci Food Agric. 2004;84:1241-1252. doi:10.1002/jsfa.1746

35. Olayinka OO, Olu-Owolabi BI, Adebowale KO. Effect of chemical modifications on thermal, rheological and morphological properties of yellow sorghum starch. J Food Sci Technol. 2015;52(12):8364-8370. doi:10.1007/s13197-015-1891-3

36. Rangelov A, Arnaudov L, Stoyanov S, Spassov T. Gelatinization of industrial starches studied by DSC and TG. Bulg Chem Commun. 2017; 49(2):422-429.

37. Bhupender SK, Rajneesh B, Baljeet SY. Physicochemical, functional, thermal and pasting properties of starches isolated from pearl millet cultivars. Int Food Res J. 2013;20:1555-1561. http://www.ifrj.upm.edu. my/20\%20(04)\%202013/6\%20IFRJ\%2020\%20(04)\%202013\%20Bhu pender\%20(390).pdf

38. Lai VMF, Lu S, Lii CY. Molecular characteristics influence retrogradation kinetics of rice amylopectins. Cereal Chem. 2000;77(3):272-278. doi:10.1094/CCHEM.2000.77.3.272

39. Shah N, Mewada KR, Meht T. Crosslinking of starch and its effect on viscosity behavior. Rev Chem Eng. 2016;32(2):265-270. doi:10. 1515/revce-2015-0047

40. Jane JL, Chen YY, Lee, LF, et al. Effects of amylopectin branch chain length and amylose content on the gelatinization and pasting properties of starch. Cereal Chem. 1999;76:629-637. doi:10.1094/CCHEM. 1999.76.5.629

41. Buchholz BA, Zahn JM, Kenward M, Slater GW, Barron AE. Flowinduced chain scission as a physical route to narrowly distributed, high molar mass polymers. Polymer. 2004;45(4):1223-1234. doi:10. 1016/j.polymer.2003.11.051

42. Hong PV, Morita N. Physicochemical properties of hydroxypropylatred and cross-linked starches from A-type and B-Type wheat starch granules. Carbohydr Polym. 2005;59(2):239-246. doi:10.1016/j.carbpol.2004.09.016

43. Daniel S, Wardana AA, Surono IS. Resistant starch content, pasting properties, and morphology of taro (Colocasia esculenta L. Schott) flour modified by heat moisture treatment. J Phys Conf Ser. 2019; 1363:012007. doi:10.1088/1742-6596/1363/1/012008

44. Yousif El, Gadallah MGE, Sorour AM. Physico-chemical and rheological properties of modified corn starches and its effect on noodle quality. Ann Agric Sci. 2012;57(1):19-27. doi:10.1016/j.aoas.2012.03.008

45. Lovedeep K, Jaspreet S, Owen JM, Harmit S. Physicochemical, rheological and structural properties of fractionated potato starches. J Food Eng. 2007;82(3):383-394. doi:10.1016/j.jfoodeng.2007.02.059

46. Tô HT, Karrila SJ, Nga LH, Karrila TT. Effect of blending and pregelatinizing order on properties of pregelatinized starch from rice and cassava. Food Res. 2020;4(1):102-112. doi:10.26656/fr.2017.4(1).245

47. Salman H, Blazek J, Lopez-Rubio A, Gilbert EP, Hanley T, Copeland L. Structure-function relationships in $A$ and $B$ granules from wheat starches of similar amylose content. Carbohydr Polym. 2009;75: 420-427. doi:10.1016/j.carbpol.2008.08.001 